\title{
PHYSICAL EDUCATION STUDENTS' KNOWLEDGE OF SELECTED SAFE AND NON-RECOMMENDED EXERCISES STRENGTHENING THE ABDOMINAL MUSCLES
}

\author{
AGNIESZKA KĘDRA, DARIUSZ CZAPROWSKI² \\ IJózef Piłsudski University of Physical Education in Warsaw, Faculty of Physical Education \\ and Sport in Biała Podlaska, Department of Posture Correction and Compensation \\ 2Józef Rusiecki University College in Olsztyn, Department of Physiotherapy \\ Mailing address: Agnieszka Kędra, Faculty of Physical Education and Sport in Biała Podlaska, \\ 2 Akademicka Street, 21-500 Biała Podlaska, tel.: +48 83 3428752, fax: +48 83 3428800, \\ e-mail: agnieszka.kedra@awf-bp.edu.pl
}

\begin{abstract}
Introduction. The aim of the study was to assess final-year physical education (PE) students' knowledge of exercises strengthening the abdominal muscles which are used in the introductory part of a PE lesson. Material and methods. The research involved 467 final-year physical education students. The group examined included undergraduate (Bachelor) and postgraduate (Master) students from four universities in Poland. A knowledge test with photographs was used to conduct the study. The students completed the knowledge test with one of the authors present. If the students had any questions regarding the exercises included in the test, they were demonstrated by the person in the photographs. The data were analysed using the MannWhitney-Wilcoxon test. Kendall's concordance coefficient was used to assess reliability and measure the agreement between the opinions of a group of experts who were asked to rate the exercises in terms of their safety and effectiveness. The calculations were made with the use of statistical and calculation software (SPSS 9.0 for Windows). An alpha value $<0.05$ was accepted as the level of significance of differences between the groups of undergraduate and postgraduate students. Results. Eighty-two participants (17.6\%) performed the task correctly, selecting all the safe exercises, 139 students (29.8\%) made one error, while 110 marked all the overloading and ineffective exercises as safe. Conclusions. The students' knowledge of safe exercises strengthening the abdominal muscles was insufficient. Both undergraduate and postgraduate students demonstrated similar knowledge concerning these exercises.
\end{abstract}

Key words: exercises, strengthening of the abdominal muscles, students' knowledge

\section{Introduction}

Exercises strengthening the abdominal muscles are commonly used in training programmes of professional athletes, recreational sport, physical education, and rehabilitation [1, 2, 3]. If selected and performed properly, such exercises serve as a basis for preventing injuries of the musculoskeletal system, stabilise body posture, and protect the spine from overload or pain $[4,5,6,7,8,9,10]$.

In the past, exercises strengthening the abdominal muscles which maximised the activity of these muscles were recommended [11, 12]. However, in the 1970s, the safety of these programmes started to be questioned since when such exercise is performed, tissues may be damaged due to the shear and compressive forces acting on the lumbar segment of the spine. Biomechanical and electromyographic (EMG) tests also revealed that certain exercises were not effective in increasing the strength of the abdominal muscles $[9,10,11,12,13,14,15,16]$. It is more beneficial to strengthen the abdominal muscles with the use of exercises which put minimal load on the lumbar segment of the spine $[1,2,3]$.

Physical exercises applied during PE lessons should be both effective and safe, as some of them, despite being effective in strengthening the abdominal muscles, may increase the shear and compressive forces acting on the spine. Some sources of loads acting on the spine include increased activity of the iliopsoas $[17,18]$ and failure to maintain the lumbo-pelvic-hip complex in a neutral position [19].

Since future PE teachers, coaches, and other persons who organise physical activity should be specialists in the field of safe and recommended exercises, the aim of the work was to assess final-year physical education students' knowledge of exercises strengthening the abdominal muscles which can be used in the introductory part of a PE lesson.

\section{Material and methods}

\section{Diagnostic tool}

On the basis of an analysis of the available literature, the authors selected a range of exercises strengthening the abdominal muscles. The exercises were assessed with regard to their effectiveness and the level of risk of musculoskeletal system overload they posed $[1,2,3,4,9,13,14,15,16,20,21,22,23,24,25,26$, $27,28]$. The literature review was performed using data bases such as MEDLINE, EBSCO, SPORTDiscus, ScienceDirect, Web of Knowledge, and Lippincott electronic journals. Only original works were taken into account. The terms used to find relevant 
publications included "exercises strengthening rectus abdominis muscle", "exercises strengthening abdominal external/internal oblique muscle”, and other phrases connected with the risk of spine overload.

The selected exercises strengthening the abdominal muscles were later used as a basis for designing the research form. A knowledge test with photographs was applied as a research tool. The research purpose and instructions were presented in the introductory part of the test. The test included photographs of 3 groups of exercises strengthening the abdominal muscles with detailed descriptions (initial position, movement, and final position). Group 1 included exercises strengthening the rectus abdominis controlled by an upper part of the body, group 2 consisted of exercises strengthening the rectus abdominis controlled by a lower part of the body, while group 3 comprised exercises strengthening the abdominal oblique muscles. Each of the three groups included 3 subgroups of exercises (A, B, and C). Subgroup A included safe exercises, subgroup B was comprised of risky exercises, and subgroup $C$ consisted of ineffective and overloading exercises (tab. 1). Exercises were included in particular subgroups (A, B, and C) on the basis of the level of overload they cause.

\section{Description of exercises strengthening the abdominal muscles (tab. 1)}

1) Exercise $1 \mathrm{~A}$ - lying in a supine position, lower limbs bent in knees and hips, feet flat on the floor, upper limbs straightened against the sides of the body. Movement - diaphragm inhalation followed by slow exhalation combined with lifting the head and shoulders (with shoulder blades touching the ground) and pulling the navel in towards the spine.

2) Exercise $1 \mathrm{~B}$ - lying in a supine position, lower limbs straightened in knees and hips. Upper limbs straightened in elbows against the sides of the body. Movement - lifting the head, shoulders, and trunk to a sedentary position. Returning to the initial supine position.

3) Exercise $1 \mathrm{C}$ - sitting on a gymnastic bench, lower limbs bent in knees and hips, feet stabilised, upper limbs lifted straight behind the head. Movement - straightening the trunk and upper limbs to the maximum. Returning to the initial position.

4) Exercise $2 \mathrm{~A}$ - lying in a supine position, lower limbs straight in knees and bent in hips at a $90^{\circ}$ angle to the floor, calves joined. Upper limbs against the sides of the body (the back of the hand touching the floor). Movement - lifting sacrum from the floor and holding this position for 3 seconds. Returning to the initial position.

5) Exercise $2 \mathrm{~B}$ - lying in a supine position with the trunk supported on forearms. Lower limbs straightened in knees and lifted $20 \mathrm{~cm}$ above the floor. Movement - scissoring lower limbs vertically.

6) Exercise $2 \mathrm{C}$ - lying in a supine position, lower limbs straightened in knees and lifted $20 \mathrm{~cm}$ above the floor. Upper limbs straightened in elbows at a $90^{\circ}$ angle to the trunk lying flat on the floor. Movement - scissoring lower limbs vertically.

7) Exercise $3 \mathrm{~A}$ - lying in a supine position, lower limbs bent in knees and hips, feet flat on the floor. Upper limbs straightened in elbows at a $90^{\circ}$ angle to the trunk lying flat on the floor. Movement - diaphragm inhalation followed by exhalation while pulling the navel in towards the spine and shifting calves $20 \mathrm{~cm}$ in a lateral plane. Returning to the initial position and changing the exercised side.

8) Exercise $3 \mathrm{~B}$ - lying in a supine position, lower limbs straightened in knees and hips lying flat on the floor. Upper limbs straightened in elbows, at a $90^{\circ}$ angle to the trunk lying flat on the floor. Movement - lifting the head, trunk, right and left upper limb, and right and left lower limb simultaneously and then, while bending the body, touching the left knee with the right hand. Returning to the initial position and changing the exercised side.

9) Exercise $3 \mathrm{C}$ - lying flat on the floor, lower limbs straightened in knees and bent in hips at a $90^{\circ}$ angle to the floor. Upper limbs straightened in elbows at a $90^{\circ}$ angle towards the trunk and lying flat on the floor. Movement - shifting lower limbs to the right side until the limbs touch the floor. Returning to the initial position and changing the exercised side.

The terminology which was used to describe the exercises is applied in physical education.

Table 1. Abdominal muscle exercises included in the knowledge test

\begin{tabular}{|l|l|l|l|l|}
\hline \multicolumn{1}{|c|}{ Subgroup } & \\
Group \\
$\begin{array}{l}\text { Exercises strengthening the rectus } \\
\text { abdominis controlled by an upper } \\
\text { part of the body }\end{array}$ \\
$\begin{array}{l}\text { Group } 2 \\
\text { Exercises strengthening the rectus } \\
\text { abdominis controlled by a lower } \\
\text { part of the body }\end{array}$
\end{tabular}




\section{Tool verification}

In order to verify the selection of the exercises, the method of expert assessment was applied. The group of experts included 24 physiotherapists and 21 physicians. The experts were given a form showing the exercises with their detailed descriptions. The task of every expert was to select the exercises which, according to their knowledge and experience, were (1) safe, (2) risky, and (3) ineffective and overloading the spine and assign them to each group and subgroup. In order not to suggest any answers, exercises from subgroups $\mathrm{A}, \mathrm{B}$, and $\mathrm{C}$ in particular groups (1, 2, and 3 ) were presented in a random order. If there were any questions regarding the way in which the exercises included in the test were performed, these exercises were demonstrated by the person who can be seen in the photographs.

\section{Sample selection}

The research included 473 final-year undergraduate (Bachelor) and postgraduate (Master) students of physical education from 4 universities in Poland. All the participants of the study were over 18 years of age. The method of two-stage cluster sampling was applied. In the first stage, universities that offer physical education programmes in particular regions of the country were randomly selected. In the second stage, groups of students (final year of studies) were selected from particular faculties (cluster stratified sampling). The numbers of students were selected with probability proportional to the numbers of final-year students at particular faculties. The analysis included students who gave written consent, i.e. 467 students (239 undergraduate Bachelor students and 228 postgraduate Master students) of physical education from the following universities: Rzeszów University, the Józef Śniadecki University of Physical Education and Sport in Gdańsk, the Józef Piłsudski University of Physical Education in Warsaw, and Holy Cross University in Kielce.

\section{Knowledge test}

The research form, i.e. the knowledge test including photographs with detailed descriptions, was presented to the students. Each subject received the same form. The task was to indicate one exercise in each group which, according to the subject, was safe for the spine and thus is recommended for use in the introductory part of a PE lesson. If, according to the respondents, the group did not include a safe exercise, the students were not to mark any exercise and were allowed to describe in detail their own version of the exercise which could be qualified as safe. In order not to suggest any answers, exercises from subgroups $\mathrm{A}, \mathrm{B}$, and $\mathrm{C}$ in particular groups (1, 2, and 3) were presented in a random order. The respondents knew about the division into groups 1,2 , and 3, but they were not informed about the subgroups, i.e. symbols $\mathrm{A}, \mathrm{B}$, and $\mathrm{C}$. The symbols were added so that the results of the research could be better presented and interpreted.

All the students completed the knowledge test during their classes or lectures at the university with one of the authors present. If there were any questions regarding the way in which the exercises included in the test were performed, these exercises were demonstrated by the person seen in the photographs. The knowledge test was anonymous and voluntary, and the study was approved by the Senate Research Ethics Committee of the Józef Piłsudski University of Physical Education in Warsaw.

\section{Statistical methods}

The collected data were analysed statistically. In order to compare the knowledge of undergraduate and postgraduate students, a non-parametric Mann-Whitney-Wilcoxon test was applied. Kendall's concordance coefficient was used to assess reliability and measure the agreement between the opinions of the experts. The calculations were made using statistical and calculation software (SPSS 9.0). The value of alpha $<0.05$ was accepted as the level of significance of differences.

\section{Results}

\section{Selection of exercises by experts}

According to $95.6 \%$ of the experts, exercise $1 C$ was the most ineffective and overloaded the lumbar segment of the spine the most out of the exercises strengthening the rectus abdominis controlled by an upper part of the body (group 1). In group 2 (exercises strengthening the rectus abdominis controlled by a lower part of the body), the exercise which was the most ineffective and most conducive to overload was exercise $2 \mathrm{C}$, which was chosen by $97.8 \%$ of the experts, while in group 3 , it was exercise $3 C$, indicated by $91.1 \%$ of the experts. The exercises that the experts identified as risky were as follows: exercise $1 \mathrm{~B}$ in group 1 (nearly 95.6\%), exercise 2B in group 2 (nearly 97.8\%), and exercise 3B in group 3 (91.1\%). In turn, the safe exercises in particular groups, according to the experts, were: exercise $1 \mathrm{~A}$ in group 1 , exercise $2 \mathrm{~A}$ in group 2 , and exercise $3 \mathrm{~A}$ in group 3. The percentage of experts who selected these exercises as safe in each of the groups was $100 \%$ (fig. 1).

The concordance coefficient in particular groups was equal to or higher than $\mathrm{W}=0.91$ (0.96; 0.98; 0.91, respectively).

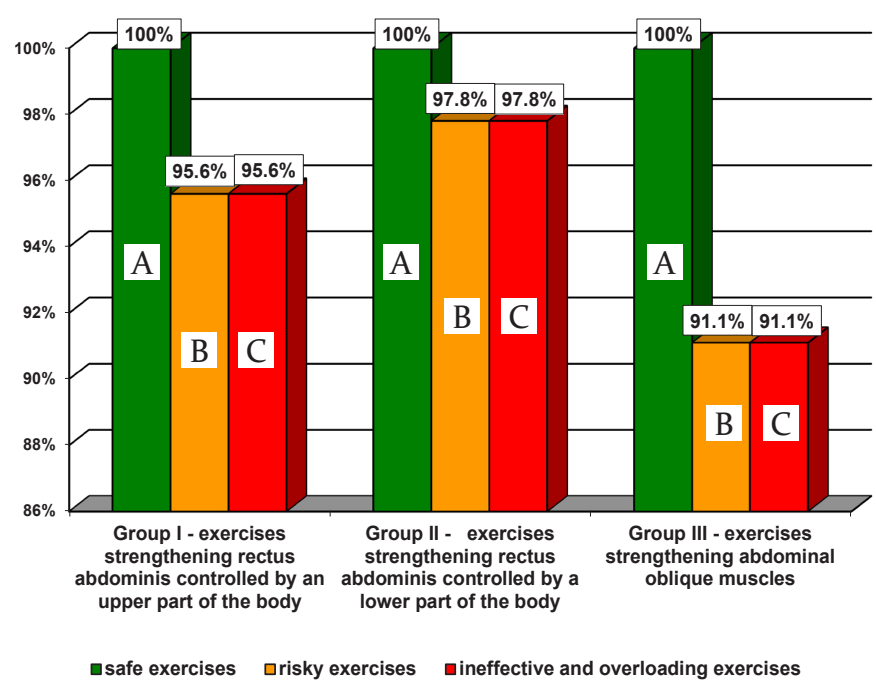

Figure 1. Percentage of experts who selected a given exercise for the following subgroups: A - safe exercises, B - risky exercises, and C ineffective and overloading exercises

\section{Selection of exercises by students}

Both the undergraduate and postgraduate students most often (177 times) selected exercise 1A as a safe one from among the exercises strengthening the rectus abdominis controlled by an upper part of the body. In turn, 113 students saw exercises $1 \mathrm{~B}$ and $1 C$ (risky and ineffective exercises, respectively) as safe. No statistically significant differences $(p>0.05)$ were noted in the selection of the safe exercise strengthening the rectus abdominis controlled by an upper part of the body made by undergraduate and postgraduate students (tab. 2). 
In the group of exercises strengthening the rectus abdominis controlled by a lower part of the body (group 2), the students (85 undergraduate and 101 postgraduate students) perceived exercise $2 \mathrm{C}$ as safe. Also, 102 undergraduate and postgraduate students selected exercise $2 \mathrm{~B}$ as a safe one (tab. 2). No significant differences ( $p>0.05)$ were noted between undergraduate and postgraduate students as far as their choice regarding the exercises strengthening the rectus abdominis controlled by a lower part of the body is concerned. overloading exercise (3C) were identified as safe by 167 undergraduate and postgraduate students. No significant differences ( $p>0.05$ ) were found between undergraduate and postgraduate students for the third group of exercises (tab. 2).

In the group of 467 students included in the research, 82 (17.6\%) made no errors and identified all the safe exercises, 139 students (29.8\%) made one error, while 110 marked all the overloading and ineffective exercises as safe (tab. 3).

Table 2. Opinions of undergraduate and postgraduate students concerning safe exercises strengthening the rectus abdominis controlled by an upper (group 1) and lower (group 2) part of the body as well as the abdominal oblique muscles (group 3$)(\mathrm{n}=467)$

\begin{tabular}{|c|c|c|c|c|c|c|c|c|c|}
\hline \multirow{2}{*}{$\begin{array}{l}\text { Subgroup of } \\
\text { exercises }\end{array}$} & \multicolumn{2}{|c|}{ A } & \multicolumn{2}{|c|}{ B } & \multicolumn{2}{|c|}{$C$} & \multirow{2}{*}{ Sum of ranks } & \multirow{2}{*}{ Z-test } & \multirow{2}{*}{$\mathrm{p}$} \\
\hline & $\mathrm{n}$ & $\%$ & $n$ & $\%$ & $\mathrm{n}$ & $\%$ & & & \\
\hline \multicolumn{10}{|c|}{ Exercises controlled by an upper part of the body (group 1) } \\
\hline UG $(n=239)$ & 177 & 74.1 & 32 & 13.4 & 30 & 12.5 & 56548.50 & \multirow{2}{*}{0.42701} & \multirow{2}{*}{0.67} \\
\hline$P G(n=228)$ & 177 & 77.6 & 15 & 6.6 & 36 & 15.8 & 52729.50 & & \\
\hline \multicolumn{10}{|c|}{ Exercises controlled by a lower part of the body (group 2) } \\
\hline UG $(n=239)$ & 98 & 41.0 & 56 & 23.4 & 85 & 35.6 & 53560.50 & \multirow{2}{*}{-1.62265} & \multirow{2}{*}{0.1} \\
\hline$P G(n=228)$ & 81 & 35.5 & 46 & 20.2 & 101 & 44.3 & 55717.50 & & \\
\hline \multicolumn{10}{|c|}{ Exercises strengthening the abdominal oblique muscles (group 3) } \\
\hline UG $(n=239)$ & 161 & 67.4 & 43 & 18.0 & 35 & 14.6 & 53946.00 & \multirow{2}{*}{-1.35821} & \multirow{2}{*}{0.17} \\
\hline$P G(n=228)$ & 139 & 61.0 & 43 & 18.8 & 46 & 20.2 & 55332.00 & & \\
\hline
\end{tabular}

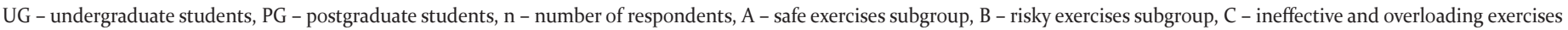
subgroup, Z-test - test for comparing two independent proportions.

In the group of exercises strengthening the abdominal oblique muscles, exercise $3 \mathrm{~A}$ was selected as a safe one most often (300 indications). The risky exercise (3B) and ineffective and

Table 3. Number of errors made by the students in the knowledge test $(\mathrm{n}=467)$

\begin{tabular}{|c|c|c|c|c|c|}
\hline $\begin{array}{l}\text { Number } \\
\text { and percentage of students }\end{array}$ & 0 & 1 & 2 & 3 & Total \\
\hline \multicolumn{6}{|c|}{ UG } \\
\hline$n$ & 43 & 68 & 75 & 53 & 239 \\
\hline$\%$ & 17.9 & 28.5 & 31.4 & 22.2 & 100 \\
\hline \multicolumn{6}{|c|}{ PG } \\
\hline$n$ & 39 & 71 & 61 & 57 & 228 \\
\hline$\%$ & 17.1 & 31.1 & 26.8 & 25.0 & 100 \\
\hline \multicolumn{6}{|c|}{ UG and $P G$} \\
\hline$n$ & 82 & 139 & 136 & 110 & 467 \\
\hline$\%$ & 17.6 & 29.8 & 29.1 & 23.5 & 100 \\
\hline
\end{tabular}

UG - undergraduate students, PG - postgraduate students, $\mathrm{n}$ - number of respondents, $\%$ - percentage value.
An analysis of the responses in the test revealed that in the majority of cases (group $1-75.8 \%$, group $2-38.3 \%$, group $3-$ $64.2 \%)$, the respondents indicated the safe exercises correctly. However, it is worth noting that when it comes to both risky and ineffective and overloading exercises in group 1, over $24 \%$ of students selected these exercises as safe ones. In groups 2 and 3 this percentage was $61 \%$ and $35 \%$, respectively (fig. 2 ).

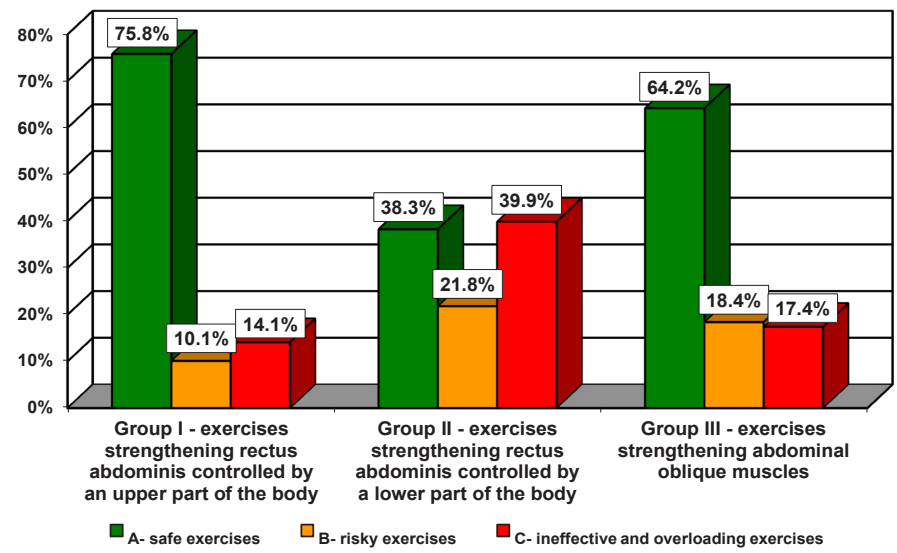

Figure 2. Results of the knowledge test: percentage of students who identified safe exercises, risky exercises, and ineffective and overloading exercises as safe $(n=467)$ 


\section{Discussion}

The aim of the work was to assess the final-year physical education students' knowledge of exercises strengthening the abdominal muscles used in the introductory part of a PE lesson. To the authors' knowledge, such research has not been carried out yet.

The research included final-year physical education students $(n=467)$ who should already be prepared for their future work. The participants of the research presented their knowledge of exercises strengthening the abdominal muscles which they gained during their classes. Additionally, during their studies, the subjects did a teaching apprenticeship, which is an obligatory part of their study programme. Over $24 \%$ of the respondents revealed a lack of knowledge of safe exercises strengthening the rectus abdominis controlled by an upper part of the body (group 1). In the group of exercises strengthening the rectus abdominis controlled by a lower part of the body (group 2) and exercises strengthening the abdominal oblique muscles (group 3), the percentage of wrong answers was over $61 \%$ and $35 \%$, respectively. In the group of 467 students, as many as 110 participants of the research identified risky as well as ineffective and overloading exercises as safe ones in all the groups. The analysis of the results revealed that both undergraduate and postgraduate students demonstrated a similar level of knowledge of exercises strengthening the rectus abdominis controlled by an upper and lower part of the body and exercises strengthening the abdominal oblique muscles ( $p>0.05)$.

The findings of the study show that the knowledge of future PE teachers concerning safe exercises strengthening the abdominal muscles is insufficient. Therefore, there is a risk that they will apply risky and inefficient exercises while conducting PE classes with children and youth.

It should be highlighted that the questions the students were asked regarded the selection of exercises which they would apply during the introductory part of a PE lesson. According to the methodology of teaching physical education, the introductory part of a lesson is aimed, among others, at preparing the body for more intensive physical effort during the main part of the lesson.

Kędra, Czaprowski, and Rutkowska [29] observed 60 PE lessons in schools at three levels of education focusing on safe, risky, and overloading exercises that were performed. The results of the research revealed that only four lessons included safe exercises. The teachers most frequently selected overloading, ineffective, and risky exercises.

Exercises strengthening the abdominal muscles are a significant element of training programmes both in professional and amateur sports as well as of rehabilitation programmes and PE lessons. Properly performed and selected exercises of the abdominal muscles are a key stabilising element [8, 27]. It is recommended that the abdominal muscles be strengthened with exercises that exert minimum load on the lumbar segment of the spine $[1,2,3]$.

While performing exercises which strengthen the abdominal muscles, it is necessary to maintain a neutral position of the lumbo-pelvic-hip complex. It is indispensable for the proper functioning of local and global muscles and simultaneously for providing the lumbar spine with support when loads are applied $[31,32]$. Additionally, in order to increase the stiffness of the sacroiliac joints, it is necessary to activate the multifidus and transversus abdominis muscles [32].

Czaprowski and Kędra [19] carried out research on a group of final-year physical education students concerning their knowledge of the role of maintaining the lumbo-pelvic-hip complex in a neutral position. Over $60 \%$ of the respondents demonstrated a lack of knowledge or insufficient knowledge regarding this issue. What is particularly significant is that, according to the results of the study, over $90 \%$ of the respondents were unable to teach a child how to control the proper position of the lumbo-pelvic-hip complex.

\section{Recommendations for the future}

The obtained results indicate that there is a need to adequately prepare physical education students so that they are able to select proper physical exercises at the initial stage of teaching and especially before the teaching apprenticeship, which is an obligatory element of their programme of studies. A lack of proper knowledge among future teachers may result in them organising exercises which may cause students participating in PE lessons to experience mechanical overload on spinal motion segments and spinal pain. The research has indicated how crucial it is to adequately prepare PE teachers to implement tasks connected with promoting health and preventing diseases of affluence including spine injuries and disorders.

\section{Conclusions}

1. The final-year physical education students' knowledge of safe exercises strengthening the rectus abdominis and abdominal oblique muscles was insufficient.

2. Both undergraduate and postgraduate students of physical education demonstrated a similar level of knowledge of exercises strengthening the abdominal muscles.

\section{Acknowledgements}

The work has been prepared under the research project of the Faculty of Physical Education and Sport in Biała Podlaska, Józef Piłsudski University of Physical Education in Warsaw - DS. 183 - financed by the Ministry of Science and Higher Education.

\section{Literature}

1. McGill S., Sharratt M., Seguin J. (1995). Loads on spinal tissues during simultaneous lifting and ventilatory challenge. Ergonomics 38(9), 1772-92.

2. Axler C., McGill S. (1997). Low back loads over a variety of abdominal exercises: searching for the safest abdominal challenge. Medicine and Science in Sports Exercise 26(6), 804-811.

3. Anderson E., Nilsson J., Ma Z., Thorstensson A. (1997). Abdominal and hip flexor muscle activation during various training exercises. European Journal of Applied Physiology 75, 115-125.

4. Juker D., McGill S., Kropf P., Steffen T. (1998). Quantitative intramuscular myoelectric activity of lumbar portions of psoas and the abdominal wall during a wide variety of tasks. Medicine and Science in Sports Exercise 30(2), 301-10.

5. Souza G., Baker L., Powers C. (2001). Electromyography activity of selected trunk muscles during dynamic spine stabilization exercises. Archives of Physical Medicine and Rehabilitation 82, 1551-1557.

6. Cissik J.M. (2002). Programming abdominal training, Part I. Strength and Conditioning Journal 24(1), 9-15. 
7. Muscolino J., Cipriani S. (2004). Pilates and the 'powerhouse' - I. Journal of Bodywork and Movement Therapies 8, $15-24$.

8. Kisner C., Colby L.A. (2007). Therapeutic exercise: foundations and techniques. Philadelphia: F.A. Davis.

9. Liebenson C. (2008). A modern approach to abdominal training-Part III: Putting it together. Journal of Bodywork and Movement Therapies 12, 31-36.

10. Pescatello L.S. (2013). ACSM's guidelines for exercise testing and prescription. Philadelphia: Lippincott Williams \& Wilkins.

11. Walters C.E., Partridge M.J. (1957). Electromyographic study of the differential action of the abdominal muscles during exercise. American Journal of Physical Medicine 36(5), 259-68.

12. Flint M. (1965). Abdominal muscle involvement during the performance of various forms of sit-up exercise. An electromyographic study. American Journal of Physical Medicine 44(5), 224-34.

13. Nachemson A., Elfstrom G. (1970). Intravital dynamic pressure measurements in lumbar discs. A study of common movements, maneuvers and exercises. Scandinavian Journal of Rehabilitation Medicine Suppl. 1, 1-40.

14. Halpern A., Bleck E. (1997). Sit-up exercises: an electromyographic study. Clinical Orthopaedics and Related Research $145,172-8$.

15. Jetté M., Sidney K., Cicutti N. (1984). A critical analysis of sit-ups: A case for the partial curl-up as a test of abdominal muscular endurance. Canadian Association of Health, Physical Education, and Recreation Journal 51(1), 4-9.

16. McGill S.M. (1995). The mechanics of torso flexion: situps and standing dynamic flexion manoeuvres. Clinical Biomechanics 10(4), 184-192.

17. Santaguida P., McGill S. (1995). The psoas major muscle: a three dimensional geometric study. Journal of Biomechanics 28, 339-345.

18. Bogduk N., Pearcy M., Hadfield G. (1992). Anatomy and biomechanics of the psoas major. Clinical Biomechanics 7, 109-119.

19. Czaprowski D., Kędra A. (2012). Control of the position of lumbo-pelvic-hip complex during physical activity: the knowledge of the students of physical education and teaching methods. Physical Education and Sport 56(1), 17-24.

20. Guimaraes A., Vaz M., De Campos M., Marantes R. (1991). The contribution of the rectus abdominis and rectus femoris in twelve selected abdominal exercises. An electromyographic study. Journal of Sports Medicine and Physical Fitness 31(2), 222-30.
21. Anderson E., Ma Z., Thorstensson A. (1998). Relative EMG levels in training exercises for abdominal and hip flexor muscles. Scandinavian Journal of Rehabilitation Medicine 30, 175-183.

22. Payne N., Gledhill N., Katzmarzyk P.T., Jamnik V. (2000). Health-related fitness, physical activity, and history of back pain. Canadian Journal of Applied Physiology 25(4), 236-49.

23. Albert W.J., Bonneau J., Stevenson J.M., Gledhill N. (2001). Back fitness and back health assessment considerations for the Canadian Physical Activity, Fitness and Lifestyle Appraisal. Canadian Journal of Applied Physiology 26(3), 291-317.

24. Konrad P., Schmitz K., Denner A. (2001). Neuromuscular evaluation of trunk-training exercises. Journal of Athletic Training 36, 109-118.

25. Willett G.M., Hyde J.E., Uhrlaub M.B., Wendel C.L., Karst G.M. (2001). Relative activity of the abdominal muscles during commonly prescribed strengthening exercises. Journal of Strength and Conditioning Research 15(4), 480-5.

26. Escamilla R.F., Babb E., Dewitt R., Jew P., Kelleher P., Burnham T. et al. (2006a). Electromyographic analysis of traditional and nontraditional abdominal exercises: Implications for rehabilitation and training. Physical Therapy 5, 656-671.

27. Escamilla R., McTaggart M., Fricklas E., DeWitt R., Kelleher P., Taylor M.K. et al. (2006b). An electromyographic analysis of commercial and common abdominal exercises: implications for rehabilitation and training. Journal of Orthopaedic and Sports Physical Therapy 36(2), 45-57.

28. Monfort-Pañego M., Vera-García F., Sánchez-Zuriaga D., Sarti-Martínez M. (2009). Electromyographic studies in abdominal exercises: a literature synthesis. Journal of Manipulative and Physiological Therapeutics 32(3), 232-44.

29. Kędra A., Czaprowski D., Rutkowska E. (2012). Risk factors for lumbar spine overload in children and teenagers during physical education class. Szkice Humanistyczne 3(29), 181190.

30. Richardson C., Hodges P.W., Hides J. (2004). Therapeutic exercise for lumbopelvic stabilization. A motor control approach for the treatment and prevention of low back pain. Livingston: Churchill.

31. Lederman E. (2010). Neuromuscular rehabilitation in manual and physical therapies. Livingston: Churchill.

32. Richardson C., Snijders C., Hides J., Damen L., Pas M., Storm J. (2002). The relation between the transversus abdominis muscles, sacroiliac joint mechanics, and low back pain. Spine 27, 399-405.

Submitted: January 22, 2016

Accepted: February 6, 2016 